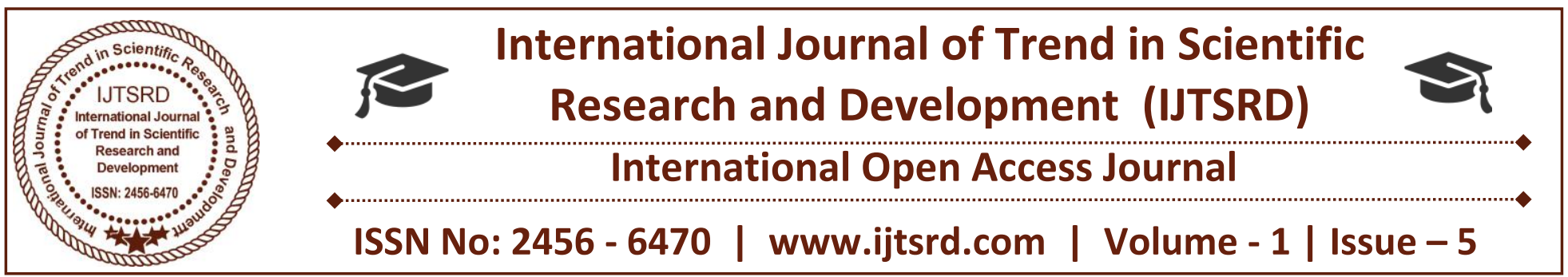

\title{
Decolorization of Textile Dye- Malachite Green
}

\author{
Dr. Jitender Kumar \\ Assistant Professor, \\ HMV College, Jalandhar, \\ Panjab, India
}

\begin{abstract}
The microbial decolorization of dyes has been of considerable interest biological treatment of the wastewater containing dyes. The bacterial isolate, Bacillus sp. was isolated from the textile effluent sample. Different parameters such as various carbon source, nitrogen source, temperature, $\mathrm{pH}$ were optimized for decolorization of Malachite green by using bacterial isolates. Bacillus sp. showed maximum dye decolorization of about $86 \%$ at $30^{\circ} \mathrm{C}$ and $\mathrm{pH} 7$ after 8 days of incubation. Maximum decolourization of malachite green $(75.80 \%)$ was observed when urea was used as nitrogen source. High decolorization extent showed the potential of the bacterial strain to be used in the decolourization of malachite green dye.
\end{abstract}

Keywords: Bacillus sp., malachite green, decolourization

\section{INTRODUCTION-}

Dyes are synthetic and aromatic molecular

Structural compounds. These are basically chemical compounds that can attach themselves to fabrics or surfaces to impart colour. Over 100,000 commercially available dyes exist and more than $7 \times 10^{5}$ metric tonnes of dyestuff are produced worldwide annually. During the dyeing processes about $10-90 \%$ of the dyestuff do not bind to the fibres and therefore, released into the sewage treatment system or the environment. Colored industrial effluents from the dyeing industries represent major environmental problems (Knapp, J. S., and Newby, P.S. 1995).
Dyeing industry effluents are one of the most problematic wastewaters to be treated not only for their high chemical oxygen demand, but also for high biological oxygen demand, suspended solids, turbidity, toxic constituents but also for color, which is the first contaminant discernible by the human eye. (O'Neill, C., Hawakes, F. R., Hawakes, D.L., and Wilox, S. J. 1999).Therefore, industrial effluents containing dyes must be treated before their discharge into the environment. Not all dyes currently used can be degraded or removed with physical and chemical processes and sometimes the degradation products are more toxic. Bioremediation can be defined as any process that uses microorganisms or their enzymes to return the environment altered by contaminants to its original condition. Dyes can be degraded and decolorized by various microorganisms such as bacteria, fungi, yeast etc. Bacteria could also degrade synthetic dyes at a faster rate but at the same time releases carcinogenic aromatic amines as degradation products which severely effects human and animal health and water. So, to overcome such problems posed by bacteria, filamentous fungi have been used for degradation and decolourization of dyes (Wong,P.K.,and Yuen,P.Y.1996).Filamentous fungi are advantageous because most of them are adapted to contamination already and they have the ability to extend through the soil. Therefore the biological methods possess many advantages over chemical and physical methods also such as possibility of degradation of dye molecules to carbon dioxide and water, formation of less sludge in addition to being environment friendly. (Hu,T.L.1994). 


\section{MATERIALS AND METHODS}

\section{$>$ Effluent samples}

Textile effluent samples were collected from the vicinity of textile industry located at Panipat. The effluent samples were collected aseptically in a plastic container and stored under refrigerated conditions in a refrigerator to avoid further changes.

\section{Chemicals}

The commonly used dye for dyeing, malachite green was used in this experiment. The other chemicals used were of analytical grade and highest purity. (Jo-Shu, C.,Tai-Shin,K.,Yun-Peng,C.,Jin-Yen,H and PingJei,L.2000).

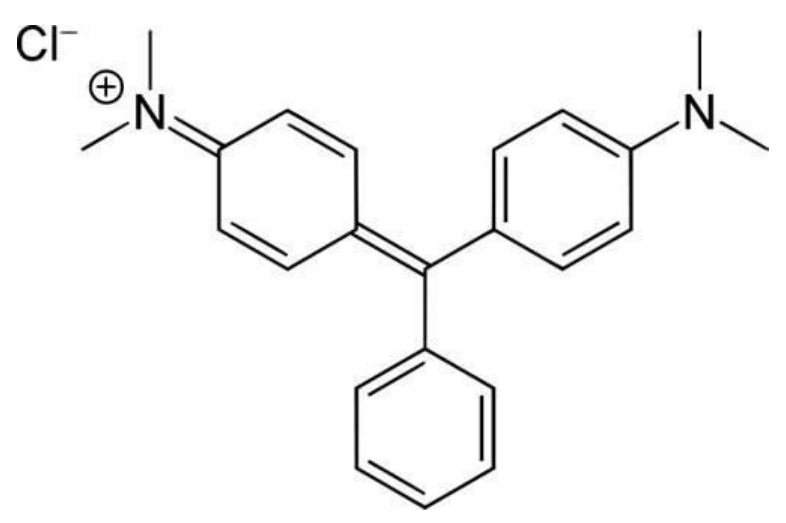

\section{Medium}

Nutrient Agar Medium Components(g/l) Peptone(5.0), Beef extract(3.0), Sodium chloride(5.0), Agar$\operatorname{agar}(20.0), \mathrm{pH}(7.2)$

* Composition of nutrient broth was same as above except that agar-agar was omitted.

All other chemicals used were of analytical grade.(Shitole,V.H.,andPanvalkar,S.S.2000).

\section{Bacterial isolation and Cultivation-}

Enrichment was carried out by "shake flask soil slurry methods" (P. L., Maharajan, M.M., Patil. D.P., Kulkarni. 2000) Ten gram of dye house effluent soil was added to $90 \mathrm{ml}$ of Zhou and Zimmermann liquid medium with $5 \mu \mathrm{g} / \mathrm{ml}$ Malachite green dye and 1.0 grams of yeast extract(Bhatt, M., Patel, M., Rawal, B., Novotný, Č., Molitoris, H. P. \& Šašek, V. 2000). The flasks were incubated on orbital shaker at $120 \mathrm{rpm}$, at $30^{\circ} \mathrm{C}$ temperature for 10 days. After 10 days the flasks were removed and $10 \mathrm{ml}$ of enriched broth was transferred to another set of above flasks containing $90 \mathrm{ml}$ liquid medium having $10 \mu \mathrm{g} / \mathrm{ml}$ of dye and 0.5 $\mathrm{g}$ of yeast extract. The flasks were again incubated on orbital shaker (at $120 \mathrm{rpm}$ ) at $30^{\circ} \mathrm{C}$. Similarly, enrichment was carried out for two more times (Verma,P.,and Madamwar, D. 2002).

\section{Determination of Minimum Inhibitory Concentrations}

One loopful of individual pure cultures from slants was transferred into one ml sterile water blank, and uniform suspension was made by using a vortex mixer. Fifty $\mu 1$ of this suspension was then spotted on Zhou and Zimmermann medium plates having different concentrations (viz. 6.25, 12.50, 25, 50 and $100 \mu \mathrm{l} / \mathrm{ml}$ ) of Malachite green dye with the help of micropipette(Yusuff, R.O.,and Sonibare, J.A. 2004) Plates were incubated at $30^{\circ} \mathrm{C}$ in a BOD incubator for three days in inverted positions. Growth of bacterial isolates was compared with the growth on plate containing no dye and noted down the minimum concentration of dye at which no growth was observed(Saunders, H.O., Brien, T., and Nixon, R. 2004)

\section{Estimation of Decolourizing Activity}

Decolourization activity was expressed in terms of percentage decolourization by the modified method given by Adedayo, O., Javadpour, S., Taylor, C., Anderson, W.A., and Moo-Young, M. 2004).and determined by monitoring the decrease in absorbance of Malachite green at $625 \mathrm{~nm}$ (Puvaneswari, N., Muthukrishnan, J.,and Gunasekaran, P. 2006)

A loopful of culture was inoculated in $30 \mathrm{ml}$ nutrient medium broth and incubated on shaker at $30^{\circ} \mathrm{C}$ for 23 days. Culture suspension $(100 \mu \mathrm{l})$ containing about $10^{8}$ cells per milli litre was transferred to the Zhou and Zimmermann liquid medium and incubated at $30^{\circ} \mathrm{C}$ on orbital shaker $(120 \mathrm{rpm})$. After every two days, one $\mathrm{ml}$ sample was taken out aseptically and centrifuged $(10,000 \mathrm{rpm}$ for $5 \mathrm{~min})$ (Mathur, N., Bhatnagar, P.,and Bakre, P. 2006) To one ml supernatant, two $\mathrm{ml}$ of water saturated 1-Butanol was added, mixed thoroughly by vortex mixer, allowed to stand for one hour till two layers of water and butanol get separated. Upper layer of butanol containing the dye was separated and absorbance was measured. Percent decolourization was calculated. Uninoculated flasks were treated as control.

Percent decolourization was calculated using formula:

$\mathrm{D}=100 *\left[\mathrm{~A}_{\text {ini }}-\mathrm{A}_{\text {obs }}\right] / \mathrm{A}_{\text {ini }}$

Where,

$\mathrm{D}=$ Percent decolourization

$\mathrm{A}_{\text {ini }}=$ Initial absorbance

$A_{\text {obs }}=$ Final absorbance 
International Journal of Trend in Scientific Research and Development (IJTSRD) ISSN: 2456-6470

Decolourization of Malachite Green Dye In The Presence of Carbon Sources

To test the ability of the isolates to decolourize dyes in the presence of various carbon sources like glucose, sucrose, sodium malate and mannitol. Flasks were prepared using mineral medium, $0.05 \%$ yeast extract and one percent carbon source. The flasks without additional carbon source served as control. The flasks were inoculated as described earlier. The flasks were incubated at $30^{\circ} \mathrm{C}$ on an orbital shaker $(120 \mathrm{rpm})$. Percent decolourization was determined after six and eight days as described earlier.

\section{Optimization of Conditions}

For optimization of various conditions like $\mathrm{pH}$, temperature and nitrogen sources for maximum decolourization of dyes, only selected isolates were used. To find the alternate nitrogen source in place of yeast extract, compounds like ammonium chloride, urea and sodium nitrate at one percent concentration were used in Zhou and Zimmermann broth without yeast decolourization was compared with that of yeast extract at 6 and 8 days. For optimization of temperature another set of flasks containing Zhou and Zimmermann broth were prepared. The flasks were incubated at different temperatures like 20, 25, 30, 35 and $40^{\circ} \mathrm{C}$ on orbital shakers $(120 \mathrm{rpm})$ and percent decolourization was determined. For optimization of $\mathrm{pH}$ for maximum decolourization $\mathrm{pH}$ 6.0, 6.5, 7.0, 7.5 and 8.0 each were prepared in Zhou and Zimmermann broth using $0.1 \mathrm{~N} \mathrm{NaOH}$ or $\mathrm{HCl}$. To $30 \mathrm{ml}$ broth 100 $\mu \mathrm{l}$ culture suspension containing $10^{8}$ cells of isolates $\mathrm{H}$ and $\mathrm{B}$ were inoculated. The flasks were incubated at $30^{\circ} \mathrm{C}$ on orbital incubator shaker. The samples were removed at 6 and 8 days and percent decolourization was determined as described earlier.

\section{RESULTS AND DISCUSSIONS}

\section{Isolation of bacterial cultures}

Few bacterial cultures were isolated from the prolonged cultures in synthetic wastewater. The isolate $\mathrm{H}$ was isolated as the most active dyedecolorizing bacteria. Selected bacterial isolate was identified on the basis of gram reaction, shape and sporulation. The bacterial isolate was gram positive, spore forming and rod shaped. The bacterial isolates were further tested for various biochemical characteristics such as oxidase test, catalase test, Voges-Proskauer reaction, citrate utilization, nitrate reduction, methyl red and urease production. Based on morphological, physiological and biochemical characteristics the isolate was tentatively grouped in the genus Bacillus (Sivaranjani,A.,Madhan,B.,and Barathidasan.K. 2013)..

Determination of optimum temperature for decolourization of Malachite green:

Optimization of temperature at which maximum decolourization could occur was also determined by incubating flasks at 20,25,30, 35 and $40^{\circ} \mathrm{C}$ and percent decolourization was determined at 6 and 8 days. In case of dye Malachite green, maximum decolourization of about 86 percent was seen when the flasks were incubated at $30^{\circ} \mathrm{C}$ followed by $25^{\circ} \mathrm{C}$ at 8 days of incubation.

\begin{tabular}{|l|l|l|}
\hline \multirow{2}{*}{$\begin{array}{l}\text { Temperature } \\
\left({ }^{\circ} \mathbf{C}\right)\end{array}$} & \multicolumn{2}{|c|}{ Malachite Green } \\
\cline { 2 - 3 } 6 days & $\mathbf{8}$ days \\
\hline $\mathbf{2 0}$ & 80.23 & 80.52 \\
\hline $\mathbf{2 5}$ & 82.36 & 82.65 \\
\hline $\mathbf{3 0}$ & 85.40 & 86.10 \\
\hline $\mathbf{3 5}$ & 81.57 & 81.96 \\
\hline $\mathbf{4 0}$ & 78.94 & 80.17 \\
\hline
\end{tabular}

Determination of optimum pH for decolourization of Malachite green:

To find out optimum $\mathrm{pH}$ for maximum decolourization of malachite green experiments were carried out at different $\mathrm{pH}$ values ranging from 6.0, $6.5,7.0,7.5$ to 8.0. The results showed that maximum decolourization was obtained at $\mathrm{pH} 7.0$ after 8 days. Maximum decolourization with isolate was found to be 85.70 percent in case of malachite green dye.

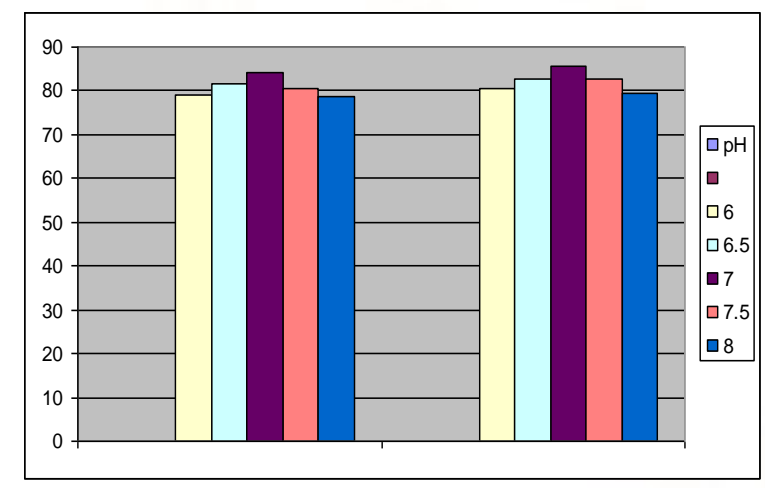

Effect of different carbon and nitrogen sources on malachite green decolourization:

To find out the best carbon source in the presence of which maximum decolourization of Malachite green dye could be obtained, Zhou and Zimmermann medium was supplemented with different carbon 
International Journal of Trend in Scientific Research and Development (IJTSRD) ISSN: 2456-6470

sources like glucose, sucrose, sodium malate and mannitol and percent decolourization at 8 days was determined. Maximum decolourization was observed with glucose as carbon source as compared to others. Maximum decolourization of 89.05 percent was obtained in Malachite green dye. Different inorganic sources of nitrogen like ammonium chloride, urea, sodium nitrate and complex organic nitrogen source like yeast extract, were used at one percent concentration. Maximum decolourization of malachite green $(75.80 \%)$ was observed when urea was used as nitrogen source by isolate followed by sodium nitrate (about $73 \%$ ) at 8 days of growth. Yeast extract was the poorest source of nitrogen(Asthana, M., Kumar, A., Prerna, V., and Gupta, P. 2014)
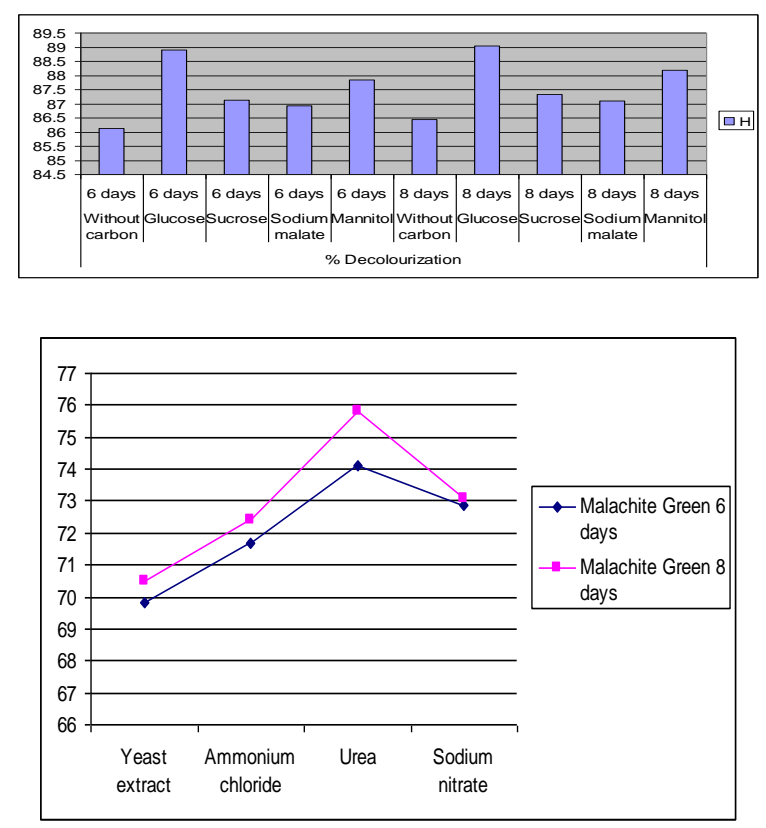

\section{CONCLUSION-}

Maximum decolorization was observed in Malachite green by bacteria isolated from textile dye effluent. Different parameters such as various carbon source, nitrogen source, temperature, $\mathrm{pH}$ showed significant effect on dye decolourization. Bacillus sp. showed highest decolorization of Malachite green dye.

\section{BIBLIOGRAPHY}

1) $\mathrm{Hu}$, T. L. (1994). Decolourization of reactive azo dyes by transformation with Pseudomonas luteola. Bioresource Technology, 49: 47 - 51.13

2) Knapp, J. S., and Newby, P. S. (1995). The microbial decolourization of an industrial effluent containing a diazo linked chromophore. Water Research, 29: 1807-1809.
3) Wong, P.K., and Yuen, P.Y. (1996). Decolourization of synthetic dyes by Klebsiella pneumoniae RS-13. Water research, 30:17361744.

4) O'Neill, C., Hawakes, F. R., Hawakes, D.L., and Wilox, S. J. (1999). Anaerobic treatment of stimulated textile effluent.Journal of Chemical Technology and Biotechnology, 74: 993 - 999.

5) Jo-Shu, C., Tai-Shin, K., Yun-Peng, C., Jin-Yen, $\mathrm{H}$ and Ping-Jei,L.(2000). Azo dye decolourization with a mutant Escherichia coli strain. Biotechnology Letters, 22: 807 - 812.

6) Shitole, V.H., 1 and Panvalkar, S.S.(2000). Bioremediation of tannery effluent. J Emp Bio Vol 1(2):10

7) Mail, P. L., Maharajan, M.M., Patil. D.P., Kulkarni. (2000) Biodecolorization of members of triphenylmethanes and azo groups of dyes. Journal of scientific and industrial research, 59: 221-224

8) Bhatt, M., Patel, M., Rawal, B., Novotný, Č., Molitoris, H. P. \& Šašek, V. (2000). Biological decolorization of the synthetic dye RBBR in contaminated soil. World Journal of Microbiology \& Biotechnology 16: 195-198

9) Verma, P., and Madamwar, D. (2002). Comparative study on transformation of azo dyes by different white rot fungi.Indian Journal of Biotechnology, 1:393-396.

10) Yusuff, R.O.,and Sonibare, J.A. (2004) Characterization of tannery industries effluents in Kaduna, Nigeria and pollution imp lications. Global nest: The Int J 6(3):212 -221.

11) Saunders, H.O., Brien, T., and Nixon, R. (2004) Tannery dye allergic contact dermatitis following paraphenylenediamine sensitization from a temporary tattoo. Aus J Dermatol 45(4):229 231

12) Adedayo, O., Javadpour, S., Taylor, C., Anderson, W.A., and Moo-Young, M. (2004). Decolourization and detoxification of methyl red by aerobic bacteria from a wastewater treatment plant. World Journal of Microbiology \& Biotechnology 20: 545-550

13) Puvaneswari, N., Muthukrishnan, J., and Gunasekaran, P. (2006) Toxicity assessment and microbial degradation of azodyes. Ind J Exp Biol 44:618-626.

14) Mathur, N., Bhatnagar, P.,and Bakre, P. (2006) Assessing mutagenicity of tannery dyes from Pali (Rajasthan) using Ames bioassay. Appl Ecol Environ Res 4(1):111 - 118 . 
International Journal of Trend in Scientific Research and Development (IJTSRD) ISSN: 2456-6470

15) Sivaranjani, A., Madhan,B., and Barathidasan.K. (2013). Decolourization of Acid Red 131 by using Shigella sp. Isolated from Tannery Effluent. International Journal of Pharmaceutical \& Biological Archives 2013; 3(5): 142-146.

16) Asthana, M., Kumar, A., Prerna, V., and Gupta, P. (2014) Tannery effluents de - coloriz ation efficiency of bacterial isolates from River Yamuna and $\mathrm{i}$ ndustrial effluents.

Int.J.Curr.Microbiol.App.Sci :3(5): $869-880$ 